\title{
Designing the Amplifon: A Locative Sound Medium to Supplement DAB Radio
}

\section{Lars Nyre}

Department of Information Science and Media Studies, University of Bergen

lars.nyre@uib.no

\section{ABSTRACT}

Radio has always had communicative concern for its listeners. It is characterized by personal address, liveness and acoustic moods that reach audiences in a variety of listening situations. Radio's communicative concern should be available for all citizens, but in fact there is rather bad reception for DAB and FM in cities due to narrow streets and other physical interference, and in addition the prominent iPhone lacks both DAB- and FM-receivers. The design project reported here aims to increase sound media's communicative concern in urban settings by 1) replacing one-way FM and DAB with two-way mobile data, 2) replacing loudspeakers with headphones, and 3) replacing the temporal news agenda with one that is locative. The article reports on the theoretical basis, design methods and empirical findings of the Amplifon prototype.

\section{KEYWORDS:}

radio, sound journalism, media design, communicative concern, locative media

The Journal of Media Innovations 2.2 (2015), 58-73.

DOI: http://dx.doi.org/10.5617/jmi.v2i2.985

http://www.journals.uio.no/index.php/TJMI

(c) Lars Nyre 2015 


\section{INTRODUCTION}

Radio was invented in steps from the late 1800 , and by 1925 most countries in the Western world had radio services with a national listenership and a public service oriented to information, entertainment and enlightenment (Nyre, 2008; Jauert \& Lowe, 2005). The radio public convenes in the kitchen, the bathroom, the workplace and the car. Stations transmit talk, music, news and advertising, all of which is distributed one-way on technical platforms such as AM, FM and DAB.

In the European radio industry the DAB platform has long been the preferred digital technology (O'Neill et.al., 2010). It replaces the analogue FM-signals with digital DAB-signals than can carry more channels, display textual information, and also provide higher sound quality for the listeners than FM, but which are otherwise essentially oneway like FM. The Norwegian government has decided to shut down the FM network in 2017, and presumably $\mathrm{DAB}$ radio stations will become the dominant form of listenership to radio in Norway from then on. The roll out of DAB is hotly debated in European countries, and in 2015 both Sweden and Denmark are hesitating to go forward with it. Many countries will continue to rely on FM distri- bution for decades to come. Radio stations, local and community stations in particular, want to cultivate their established listenership on FM.

There is little innovation inside this established sector of the radio industry. However, there has been much innovation from the outside. Radio started to become a legacy medium with the emergence of online music and talk providers in the 1990s. Streaming audio through modems and broadband from ca. 1993 has now become a widespread, if only supplementary, distribution platform for radio. Another significant contribution was file sharing from ca. 1994, with Napster, PirateBay and hard disks full of downloaded mp3-music. In the 200os music services with rights management made digital audio consumption widespread to the extent that CD sales plummeted. Podcasting (ca. 2005) has in a short period of time become a remarkably well-established means of listening to recorded music and speech, audio books, sermons and more. There is a tendency for the content to be "educational" and typically made by public service broadcasters or big newspapers, but there is also a healthy flora of independent producers with innovative content.

Headphones are the main interface for listening to the above-mentioned types of audio. Every day tens of thousands move through cities like Bergen, Oslo or Stockholm, listening to something in their headphones throughout the journey. Urban headphone listeners typically curate their audio content from a smartphone. SoundCloud (2007) and $\mathrm{Au}-$ dioBoom (2009) distribute such amateur productions as part of their service, and are contributing to an audio literacy that can be compared to the video literacy inspired by YouTube. Production and social sharing of audio files has become a hobby or a living for many people, and contributes to an increased audio literacy among the audiences.

There are interesting new audio designs for the smartphone. The mobile app Capsule.FM (see $\mathrm{http}$ ://early.capsule.fm/) presents live editorial content, read out by an artificial voice, combined with music accessed from your mobile phone. Alongside companies that explore editorial designs there are companies that produce software for targeted advertising to mobile audio players (e.g. Exaget at http://www.exaget.com). Here listeners' user history and preferences are analysed to so that they will receive personalized advertising during ad breaks. Another strand of development is audio recognition and filtering applications like Soundhound (2009). They can analyse live sound with advanced algorithms, and recognize music artists, 
melodies, bird calls, car engine brands and more. Alongside these innovations, there is a long-standing experimentation with speech recognition and artificial voices for mobile phones and increasingly smart watches.

It seems clear that the audio media industry is quite versatile, and that there is a range of technical and cultural innovations that can be recombined and further explored with the aim of recreating radio's communicative concern in a new technological setting. Legacy radio stands at risk of not having proper public concern for headphone listeners, and in this sense there is a design opportunity that should be explored. The research question is: Can radio's personal address, liveness and acoustic moods be reconstructed in digital mobile networks for urban headphone listeners?

The project name "Amplifon" refers to an ongoing research project in Bergen, Norway. The practical experimentation is conducted by 2nd year students in the new media bachelor programme, in the module called "Journalistic mobile applications" (Nyre, 2014b). The word suggests an amplification of phonemes; that is, a strengthening of the meaningful sounds of a society. We share the quirky Latin-Greek name "ampli-fon" with several other initiatives, and we cannot claim any rights to it. "Amplifon" is the name of a European hearing aid manufacturer with 5,700 specialist centres in over 20 countries (see http://www.amplifon. co.uk/), and "Ampli-phone" is the name of an acoustic loudspeaker for iphones produced in California, USA (see http://www.ampli-phone.com/ Welcome.html).

\section{Summary:}

The article first presents a theory of communicative concern, before explicating the exact way in which a locative sound medium can produce such concern. After that, the media design method applied in making the Amplifon prototypes is presented. The main analysis discusses how to 1) replace one-way FM and DAB with two-way mobile data, 2) replace loudspeakers with headphones, and 3) replace the temporal news agenda with one that is locative. In the conclusion we summarize the findings and discuss strengths and weaknesses of the Amplifon project.

\section{THEORY: CONSTRUCTION OF COMMUNICATIVE CONCERN}

The idea of "communicative concern" comes out of phenomenology and Martin Heidegger's existential philosophy. Paddy Scannell is renowned for adapting this way of thinking to media studies, and we will start from his perspective. Scannell writes that "we now live in a totally technologized world. To understand our 'conditions of existence' demands that we address the question of technology as constitutive of the world we live in" (Scannell, 2014: xi). Technologies have care-structures which result from the "thought, effort, work, intention and attention" that has gone into their realization (Scannell, 2014: 66). Regarding media, Scannell compares the images from a surveillance camera in a shopping mall with the images from a Saturday night TV-production. In the first type there is no concern, and no care for the enjoyment, learning and thinking of the person looking at it. Good TV and radio have a carefully produced concern for their listeners (Scannell, 2014: 98). These care structures are "seen but unnoticed". We typically don't realize what the care structures consist of until after the medium has started to fade, or when the technology breaks down. 
Nick Couldry (2012: 15) is hesitant towards Scannell's "totally technologized world" when he writes that "we no longer have a way of living together without media, and we don't yet know how to live well with media". Couldry presents a challenge that media researchers can take up. What would be the characteristics of media that we can all live well with? Researchers can test out new technologies and forms of content that are tailor-made to create communicative concern. John Dewey recommends that researchers try to construct technologies with good consequences for the public, which is yet another way of asking for increased concern. Dewey argues that "the public consists of all those who are affected by the indirect consequences of transactions to such an extent that it is deemed necessary to have those consequences systematically cared for" (Dewey, 1927/1991: 49). In Nordic and European countries public service broadcasting has been "public" in approximately the way Dewey argues, with a systematic care for information, entertainment and education needs among the citizens.

The construction of good consequences is a continuous learning process. The labour involved in creating communicative concern is done by a variety of professions and interest groups includ- ing journalists, musicians, interviewees, amateur participants, etc. They should all behave in a politically intelligent way, according to Dewey (1960). He argues that to be human implies a reflexive consciousness about goals and values, and this he calls intelligence. Intelligence is "conduct in which the individual thinks and judges for himself, considers whether a purpose is good or right, decides and chooses, and does not accept the standards of his group without reflection" (Dewey 1960: x). Dewey argues that citizens are required to be acutely aware of their social surroundings, and must be prepared to speak up in public about what improves and impedes the life of the community, and act in ways that will presumably have good consequences for all.

Following up Dewey's constructive approach, DiSalvo (2009: 49) investigates more directly the ways in which technologies intersect with publics. "[P]ublics are constructed, and [...] the products and processes of design might contribute to the construction of publics". Publics are things, and therefore they can be changed in quite concrete ways. DiSalvo recommends design tactics, which are "adjustments to, appropriations, or manipulations of design products and processes to accom- modate purposes beyond the common, often historically and professionally constrained, purposes of design" (2009: 49). The change-process could also be one of replacements: that is, replacing an established technological component with a novel one. The question then becomes: What technologies can and should be replaced in order to facilitate more communicative concern in a medium, and what kind of new communication is likely to occur if said replacement is effectuated?

This replacement approach to media design is clearly not value-neutral. On the contrary, it is explicitly normative due to the implicit request for reform. Examples of such research are democratic talk radio with minimal editorial control (Nyre, 2007) and locative local journalism for mobile phones (Nyre et.al., 2012). Researchers should explore beneficial public communication qualities regardless of how difficult or expensive it would be to make them. Academic prototypes are often marketagnostic, but adhere to various types of research ethics. One such framework is "responsible research innovation" (RRI), which currently informs much of the design and innovation projects under the Horizon2020 umbrella. "Responsible innovation means taking care of the future through collec- 
tive stewardship of science and innovation in the present" (Stilgoe et.al., 2013: 1570). They identify anticipation as an important dimension of finding out what is good and beneficial:

Anticipation prompts researchers and organizations to ask 'what if ...?' questions [...] to consider [...] what is known, what is likely, what is plausible and what is possible. Anticipation involves systematic thinking aimed at increasing resilience, while revealing new opportunities for innovation (1570).

Such an approach also implies that the construction project evolves systematically and patiently over a long time period, replacing components and behaviours along the way. Academic prototyping is not limited by the same forces as real media, and therefore the team can try out sensors, interfaces and content genres that don't necessarily have any commercial potential, and do so for a number of years before drawing conclusions. The Amplifon project adjusts the responsible research innovation approach to media research, and in particular it explores the potential of locative technologies.
HYPOTHESIS: LOCATIVE SOUND JOURNALISM INCREASES THE PUBLIC CONCERN FOR URBAN HEADPHONE

\section{LISTENERS}

As stated at the beginning, this article starts from the hypothesis that it is possible to increase the communicative concern of (the medium until now known as) radio. We will now specify in detail the locative program of action governing the Amplifon prototypes.

The program of action is intended to increase the communicative concern for urban listeners by helping them to take their eyes away from the mobile screen, lift their head and look around - guided by the personal address, liveness and acoustic moods established in legacy radio. The sound productions aim to create a "mental image" of the surroundings in the listeners, and as such sensitize them to a given neighbourhood, road, park, public building, etc. The slogan for such a radio station could be "Free your eyes, and your mind will follow".

The Amplifon is based on using GPS and cell towers to creates different areas with different types of sound content - basically speech genres such as news, live talk and lectures - plus music, jingles, natural sounds, etc.

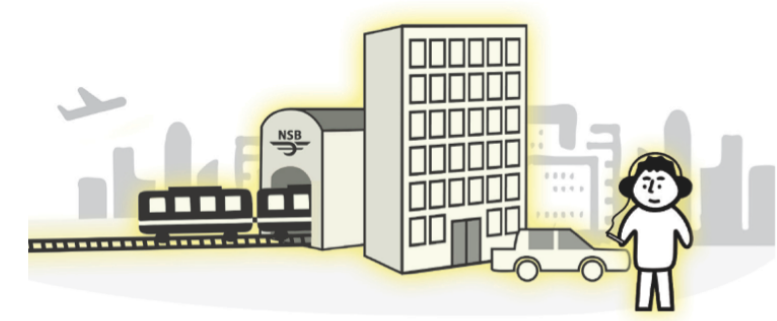

Figure 1: Amplifon coverage area. Figure by Stig Hovlandsdal Øvreås.

Figure 1 sketches the basic user interface of Amplifon, distinguishing between a yellow-hue inzone suggesting the coverage area and a grey scale out-zone where the medium is not active. The main coverage area is by definition a public area, and the journalists talk about it in spoken words, debate, live interviews, etc. The main location in figure 1 is the train station, with its endless transit of people throughout the day. The Amplifon cultivates personal address, liveness and acoustic moods to create communicative concern, and the topics are most interesting right here. The visual dimension is very important, in that hosts can draw the listeners' attention to various objects or events going on in the coverage area. Outside the coverage area there is a middle zone with music and jingles, making you aware that you are entering or leaving a public 
space in the main coverage area. It is a zone where listeners are kept on the alert. In this area of the medium there will be a particular acoustic mood that can change with the weather or other factors. Beyond the middle zone the medium goes silent. It is a kind of 'frontier' beyond which there is no editorial coverage and no reason to keep the listeners on the alert.

We rely on insights from sociology, geography and media studies to identify our location-aware principle for sound journalism. Early works include Lynch (1960) who created a vocabulary for the paths, edges, districts, nodes and landmarks that people learn to navigate by, while Milgram (1976) studied people's capacity for making mental maps of their everyday surroundings. Casey (1993) wrote a reappraisal of place that offers a philosophical foundation for studies of location information in modern societies. Steinbock (2005) outlines new mobile services that are becoming widespread, and Urry (2007) described the many types of movement and navigation in everyday life. In recent years the augmentation of behaviour by new media based on GPS and mobility have been explored by Gordon and de Souza e Silva (2011), Wilken and Goggin (2014) and others.
Among the established insights is the distinction between location-oriented and location-aware media (Øie, 2012). Location-oriented media have existed as long as any medium, and include maps, local newspapers and other media for addressing specific locations in their reporting. Locationaware media require real-time access to precise GPS information in the user >s device, and the information delivered by the medium will be continuously adapted to the listener>s current position. The latter technology has far greater potential for situational concern than the former, especially during movements of various types.

Behrendt (2015) distinguishes between location-aware genres, and her specification of "placed sounds" is particularly relevant: "Artists or designers curate the distribution of sounds in (outdoor) spaces, often - but not exclusively - using GPS" (7). A key part of "placed sound" experiences is that the audience can only access the located content when they are physically present in the specific geographic location. Their GPS location triggers sound playback (2015: 8). Behrendt (2012) is particularly concerned with the role of walking as a form of interaction with locative audio, and we share this agenda as will become clear below.

\section{DESIGN METHOD}

Students built the Amplifon as a series of two web applications under supervision by the research team in the spring of 2014. The result can be called a "low fidelity prototype" in that it presents proof of concept rather a fully functional and user-tested prototype. Research-based prototyping is an established genre in design science, pedagogy and other fields, but is less common in media and journalism scholarship. Liestøl (2009; 2013) has introduced the term "synthetic-analytic" research to distinguish it from the more common "critical-analytic" approach. Synthetic projects aim to create a new design as a way of exploring and often also critiquing a relevant media topic.

A range of media designs have been built that explore locative information in an academic way, for example Liestøl (2009) uses 3D graphics display for archaeological sites; Tessem, Johansen \& Veres (2013) use locative information services for search and factual information; Løvlie (2011) uses read-aloud excerpts from fiction describing the given place; and Øie (2015) uses locative local journalism in text and photos. These projects play with the richness of touch screens, visuals, audio 
Step 1: Formulate a program of action (or reformulate an existing program) for a medium. I

Step 2: Build a prototype with specified interfaces, signals and platforms. $\downarrow$

Step 3: Try out different procedures for editorial content and genres. I

Step 4: Evaluate the prototype and content

with test-users, and make improvements.

Step 5: Evaluate the program of action in

light of the empirical findings, and if

necessary return to step 1 t

Step 6: Establish a company and an innovation strategy for the new medium.

Figure 2: How to build and evaluate an academic media prototype. and GPS to create new, location-aware genres. Fagerjord (2015) presents an explicitly auditory locative design, where church music is "located" in Roman churches and listened to in the Musica Romana app while being in the corresponding church. Fagerjord reminds us that people's understanding of the content is hermeneutical: "Genres are about symbolic structures that create expectations and meaning in an audience; hence, we need to inspect such meaning-making properties when undertaking our research" (2015: 119). Other prototypes have been made that explore the meaning-making potential "placed sounds," such as Toronto's Park Walk project (Ladly, 2008), and Montreal's Rwanda Remembrance 53 minute walk (High, 2013). These are interesting projects, but none of them deal with radio's communicative concern in a journalistic way. The original contribution of the Amplifon project is the explicit focus on journalism and news in an auditory, locative context.

The project team works according to the "medium design method" (Nyre, 2014), which stipulates particular regard for a "program of action" or a conceptual model of what the medium is supposed to achieve. This approach is aligned with the RRI paradigm presented above.
Figure 2 shows a series of stages that should be followed in order to go through with a responsible, synthetic-analytic media research project. As the figure shows, the method consists of the following steps: First, formulating a program of action where the communicative objective or function of the medium is specified. Second, building a prototype medium with hardware, software, machinery, etc. Third, making editorial content for the medium, and trying out the prototype and content on testusers. Fourth, evaluating the program of action in light of the trials and analyses, and if necessary returning to step 1 and trying out another direction. Finally, establishing a real media outlet in a given city. The model carries an underlying time-dimension. Since each step involves empirical data gathering and analysis, it can take eight to ten years for the full cycle of research steps to be completed.

Before considering a market-oriented launch the communicative concern of the medium must have been evaluated and confirmed in a careful way. The return arrows show two levels of evaluation. The inner return arrow relates to the individual empirical efforts, and suggests that the team may have to return to step 2 and/or 3 if it is found that the prototype and content do not (yet) result 
in the stipulated communicative concern. The outer return arrow suggests that the entire program of action may have to be revised or cancelled if the empirical testing does not corroborate it. The small arrows leading downwards from box to box show the (unlikely) scenario that all all aspects of the design process support the program of action. This method culminates with the launch of a complete new medium, tried and tested in as many relevant ways as possible, or with a shutdown of the project. The Amplifon project is presently at the third stage of the media design process in figure 2. We have formulated a program of action, created two simple prototypes, and made sound content for them, so it is too early to conclude about its fate.

The description below is based on empirical data from the two initial variations of the prototype; including the creative activities programming web apps, making creative content in the form of news, reportage and music playlists, and addressing headphone users as implied listeners. Three teachers and eleven bachelor students were involved in the data gathering. The description is a proof-of-concept only. It stipulates the functionality that we wish to have for the Amplifon, but which is not yet built as a fully functional application.
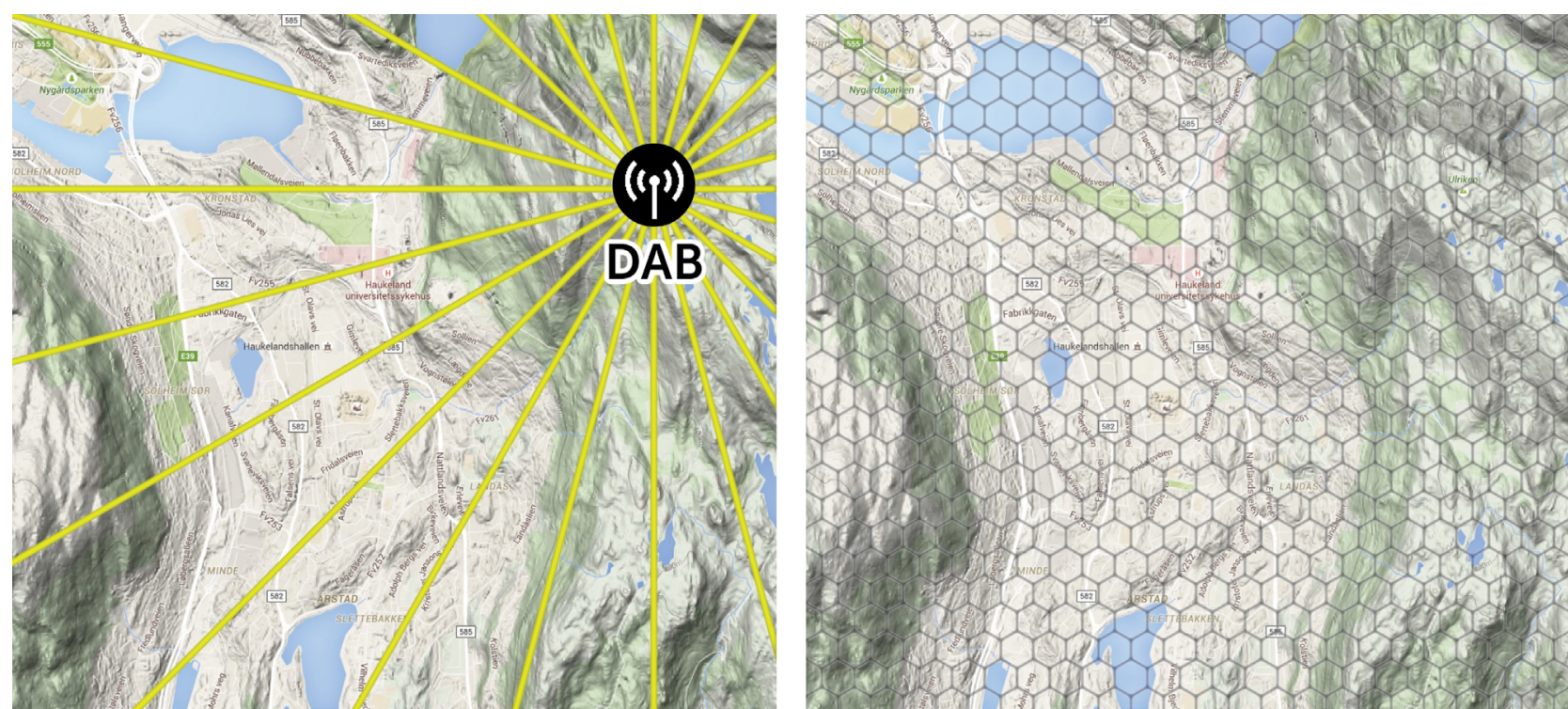

Figure 3: DAB signals vs. mobile cell signals. Figure by Stig Hovlandsdal Øvreås.

\section{PLATFORM: MOBILE DATA WITH GPS} INSTEAD OF DAB

Now we will go through the first technical replacement that the Amplifon proposes: Two-way mobile data that hugs the ground instead of one-way broadcast signals from mountaintops.

The signal platform is based on mobile data networks and Wi-Fi instead of mountaintop sig- nalling like FM and DAB. A locative medium must necessarily be built up from the human centres in a specific topography. The Amplifon is located in the Western part of Norway with its fjords, mountains and challenging conditions for transport and communication, and its centre is in the city of Bergen.

Figure 3 shows how DAB signals radiate out from the Ulriken Tower and cover the Bergen valley as a total, whereas cellular signals rely on a large 
number of signalling towers that cover specific areas that we call polygons. Although the cellular signals can reach all positions in the grid, unlike DAB signals they can also be directed only to some areas within their total reach. Unlike the DAB platform, the mobile data platform can be "lit up" as a route through a geographical area by "turning off" other polygons. This is an artificial limitation that a project imposes on itself, and not something required by the mobile data platform. The principle builds on simple adaptations of existing technology. The American GPS system is an essential feature of any locative infrastructure in Norway, at least for the time being. It is also necessary to use $3 \mathrm{G}$ data transfer from antennas and towers constructed by commercial telecommunications companies such as Telenor and Teliasonera. Notice that in principle the technical platform for Amplifon can be built independently of commercial providers of bandwidth. It could have been constructed by using a series of local area networks to send and receive the signals. However, for the foreseeable future it is most likely that the Amplifon will run on commercial services. Several other signalling technologies on the mobile phone can be employed for augmenting the local surroundings, like Bluetooth, infrared, RFID and near-field communication (NFC).
Signals can be routed to polygons in a myriad of prescribed ways that are controlled by algorithms. They can be programmed to create responsive polygons on any scale, but the Amplifon is currently restricted to the distances involved in walking and taking a suburban train, which can most practically be measured in meters and kilometres. The Amplifon grid is conceptualized to cover a limited geographical area very densely, instead of covering a large, perhaps even international area, very thinly.
INTERFACE: HEADPHONES INSTEAD OF LOUDSPEAKERS

The second replacement that the Amplifon proposes is to shift the focus from loudspeakers to headphones, and address listeners who wear headphones individually in mobile circumstances instead of listening to loudspeakers in rooms and cars where people might listen together.

With such a switch the implied audience would be urban listeners, commuting back and forth every day, jogging, walking or strolling through the city with time to lend an ear.

Headphones are implied in a large number of studies of music listening via portable devices like the Walkman, iPod, etc. (du Guy et.al., 1997; Bull, 2000; Simun 2009). Researchers have documented the solitary and individualistic character of headphone listening. Simun (2009: 922) shows how people in London use the mp3-player to shape their environment, and build a protective shield around them. Burns and Sawyer (2010: 97) show that people use the portable music player as a defense mechanism against encounters with other people. Bull (2007: 5) reminds us that the experience of the solitary individual is wanted, and considered positive: "The desire for solitude in the au- 
tomobile is mirrored in the desire for solitude in the street and the home as many retreat into the most private spaces of their already privatized home". It is against this background that the Amplifon content is produced for headphone listeners. The people who walk around and use public transport in a big city should to a larger degree experience public service content that is tailor-made for headphones, and that consequently shows communicative concern for them.

Broadcasters must realize that the radio listener is primarily a smartphone user, and will be engaged in personal communication (calls, texts, emails), games, social media and various degrees of life logging while listening to sound. People use a variety of apps that register walking, jogging and other types of transport, and these apps locate the user in an environment of restaurants, shops and leisure activities (for example Moves, RunKeeper, GoogleMaps and TripAdvisor). These locative apps can register almost everything you do, so you can quantify your activities and compare your latest efforts with previous ones. The Amplifon attempts to place the sound journalism in this new user environment.
Noise-cancelling headphones are of particular interest. People often have poor listening conditions during the periods of transit - even when wearing headphones or ear buds. Urban environments are typically very noisy, due to motorized traffic, machinery, alarms, sirens, human noise and the deep background drone that all big cities contain. The noise can sometimes be so loud that people get hearing damage, and it can make music or talk unintelligible, and interrupt your train of thought. All of this increases frustration instead of concentration.

Headphones can be "smart"; that is, contain a mini-computer with novel functionality that connects to the apps on the phone. Bluetooth headphones can have password-protected access to a user profile, where the listener's favourite audio settings are remembered, and all kinds of already established features of user profiling can be applied.

The Amplifon prototypes from 2014 do not have user profiling, and the user interaction is limited to influencing the content by deciding where you want to go. By walking from story to story in medium A and entering and exiting the tram line in medium $B$ the listeners interact with the medium, and make it launch the stories attached to their location (more about this below).

Many successful services that combine information with location are based on algorithms for user profiling and tracking, like Foursquare and Facebook. Such companies store large quantities of metadata about the actions performed on the phone, and analyse it to present content that is likely to satisfy the listener's taste, and which is tailored to the tendencies of behaviour disclosed by the tracking. This type of predictive content supply is a standard feature whcih will not be necessarily taken up in the Amplifon project because of its adherence to the ideals of public service broadcasting. We cannot leave the decisions about which content to present to the users to an algorithm. There has to be a core selection of content that every citizen in the state should relate to on an equal basis. Personal and personalized curating is not enough; there must also be authoritative editorial content. 


\section{CONTENT: LOCATIVE INSTEAD OF} TEMPORAL JOURNALISM

The third, and crucial, replacement that the Amplifon proposes relates to editorial procedures more than technologies. The production of new journalism and reportage is reoriented from a temporal "breaking-news" ideal to location-oriented procedures for reporting. As suggested, location is an important quality also in traditional journalism. Local newspapers, radio stations and other media have always addressed the local sphere topically, but this does not have the same experiential status as something location aware. It means that the medium is sensitive to the local situation of each single listener simultaneously, and presents content accordingly.

This article presumes that locative content can increase communicative concern for headphone listeners in urban settings. Here we must connect to the fact that we humans have a spatial understanding of our surroundings that can be called a mental image (Lynch 1960). This is your personal perspective on the landscape you are in right now. It is a "point position" from which you can operate, move about and find your way to other places.

In recent years there has been research on spe- cifically locative narrative practices (Forman, 2014; Väätäjä, 2014). Øie (2015) analyses news narratives in the locative journalism prototype LocaNews, and finds reason to distinguish three narrative figures that are conductive to locative journalism: secondperson address, movement imperatives and utility formulations. A large number of articles explicitly addressed the reader as "you", and asked the reader to move physically closer to see something, or alternatively to avoid something. Utility formulations deal with topics that potentially generate autonomous action, such as opening hours, times for concerts, and prices of goods (Øie, 2015).

Following this advice, Amplifon's journalism caters actively to the listeners' visual experience of their surroundings while listening to the program. Navigation requires a mental image of how your surroundings are structured, and locative journalism must construct a high quality, well-informed "image" of the surroundings, for listeners to engage with directly, and with growing subtlety. The objective is for this sound experience to come across as what Lynch calls "imageability" (1960: 9). He refers to your surroundings as having good or bad imageability depending on their character, but he did not conceive of it as something that could be stimulated through journalism. An example of "imageabil- ity" is from Fagerjord (2011), who designed a locative mobile app with spoken historical information about music associated with cathedrals in Rome, plus where said music played in the very space it was originally rehearsed and performed.

The Amplifon is a locative medium in the sense that the rhetorical address of news is reoriented from time to space. The news is in the same place all day long. It belongs to this particular place, attached to it and explaining it in a variety of genres. While such news can of course also be updated like regular news, the topics are closely associated with this place. 


\section{PROCEDURE A: WALK-BY-REPORTAGE}

This prototype was dubbed "New in Bergen". It tries out journalism in the genre that would be called "enlightenment" in the public service broadcasting paradigm, and consists of a number of 3-4 minute sound documentaries with topics that are carefully prepared to fit into the given location, and created with real sounds and sound effects.

The sound journalism is produced in a traditional way, using the established narrative structure of radio reportage, and the narrator adjusts her voice to the intended mood of the reportage. In a story about the historical fortress in Bergen she is serious and informative, while in a lighter story about rumours of ghosts at the Fløyen Mountain she is enthusiastically scared. The novelty lies not in the production qualities of the reportage, but in the limited situation in which it can be heard.

The listener is supposed to be walking through the catchment area in a self-decided pattern that orients to the location of the documentaries, but is not determined by them. Figure 4 shows a version of such movement through the city of Bergen. The lit-up yellow polygons suggest the zones where the documentaries can be listened to, the lighter shades show the musical transition zones that link

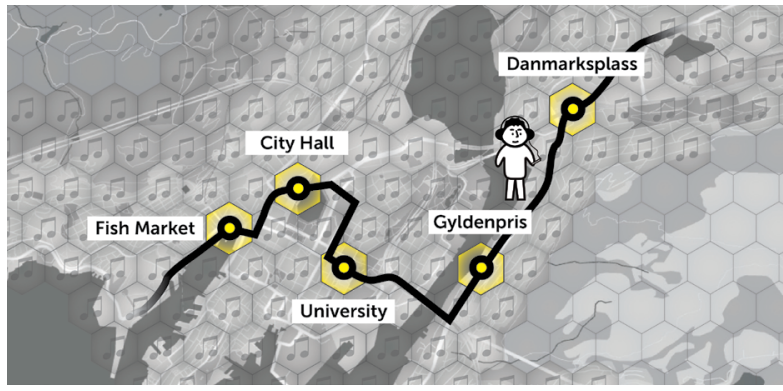

Figure 4: Walk-by-reportage. Figure by Stig Hovlandsdal Øvreås.

the documentaries temporally, and makes the medium recognizable across the coverage area. The music-based areas function as pauses in the verbal programming, and visual cues in the application inform the user about where to walk to in order to listen to more content.

The presumed listeners are tourists and visitors who are new to Bergen, as well as local inhabitants who want to learn more about history of their city. In line with traditional educational radio it is presumed that the listener is genuinely interested in learning, and that they will take on the challenge of walking around the city, and "augment" what they see with what they listen to in medium A. They are hence not presumed to be busy, but rather they are relaxed, open-minded and engaged in their physical surroundings.

\section{PROCEDURE B: SITTING-IN-THE-TRAIN-NEWS}

The second "interface probe" was dubbed "Railio", suggesting its objective of presenting news along the Bergen Light Rail. It tries out journalism in the genre that would be called news and traffic radio in the public service broadcasting paradigm. Medium B consists of a series of 1-2 minute news bulletins and news reportages located betwen the stations along the railroad, and again the topics are carefully prepared to fit the location. The stations are busy hubs where music, jingles and short advertisements are more suitable than news stories.

Users presumably walk from their house to the tramline, and are sitting still while listening. The stories are produced for being listened to in the rail carriages, where in several cases the cars will travel past the places and buildings involved in the news stories. The news reader speaks in a neutral, but lively voice, and his reports deal with a fatal bus accident at the Byparken Station, the next football match to take place near the Brann Station, and news about a cultural event at Fantoft Station.

Figure 5 shows the technical grid for medium B, represented by an arc from the City Centre (left hand side) through the Bergen Valley to Danmarksplass, Wergeland and beyond (right hand 


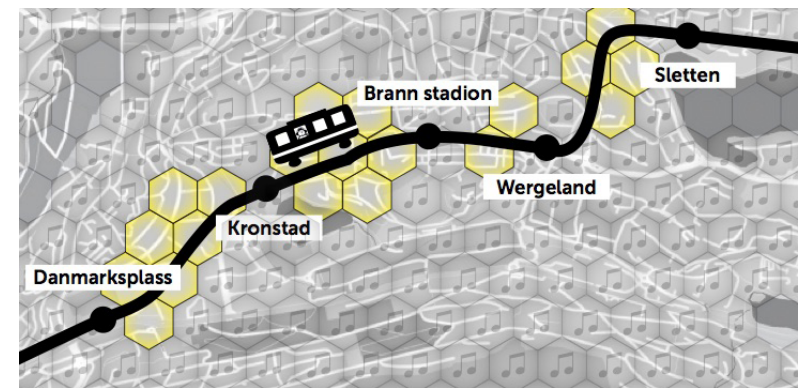

Figure 5: Sitting-in-the-train-news. Figure by Stig Hovlandsdal Øvreås.

side). The bold line with small circles represent the railroad and its stations. The news content is presented in the yellow polygon areas surrounding the stations, while music and jingles are presented in entire surrounding area. The locative principle is the same as for "New in Bergen", in that music is used as a secondary feature while the listener approaches the railroad. It was a challenge to make content that truly defends its function of only being available in the carriages, and the students struggled with it.

The music selection is quite traditional, with a combination of well-known pop and some slightly more obscure tracks to surprise the listeners. In the next iteration of medium B more work will be done to differentiate between different moods, either for the listener to select freely, or a differentiation between morning, midday and afternoon moods created by a music producer.

The implied listenership is everybody who lives and works along the built-up area along the tramline, and who regularly sits for up to 30 minutes in the carriage two times a day. It is presumed that listeners are preoccupied with their impending projects, and that they will listen somewhat absentmindedly to the program. "Railio" takes this listener attitude into consideration by having rather short news stories, and making sure that all stories start when the train leaves a station and end before it reaches the next. A combination of GPS information and good timing makes this feasible. Ideally, this hyper local radio journalism should address any and all situations that are newsworthy for the people living in the catchment area. Over time this way of doing things would put the citizens in sensitive contact with their geographical, social and political surroundings, presumably in a stronger way than the present media configurations do.

\section{CONCLUSION}

Summing up the project, Amplifon aims at finding new care structures for legacy radio, so that it also shows communicative concern for its mobile, urban headphone listeners. We explore journalistic genres that fit with the situation of urban navigators, and where the hallmarks of radio - personal address, liveness and acoustic moods - are tailored to the mobile listening situation.

We have found that there is reason to pursue three main replacements to create this new sound medium: 1) replacing one-way FM and DAB with two-way mobile data to increase the level of signal control, for example making a coverage area that follows a suburban train line; 2) replacing loudspeakers with headphones, and producing the acoustic image accordingly; and 3), replacing the temporal news agenda with one that is locative. So far, we have tested two procedures, "Walk-byreportage" and "Sitting-in-the-train-news".

This project is driven by a critical attitude towards the present conditions in Norwegian radio. Despite the wealth of innovation in digital media in general, there is little novelty in public service radio. The democratic potential is not explored with sufficient rigor (Nyre, 2011). Podcasting, streaming 
audio and other digital audio technologies are used as supplements to the traditional broadcast service, but their communicative potential is not explored as a potential mainframe for radio. As long as legacy radio continues to prioritize $\mathrm{DAB}$ and FM there is a need for alternative design and innovation just to be on the safe side.

The medium design method has limitations that must be stressed in closing. The Amplifon, as an ideal-typical medium design, is fundamentally a research project and not a new medium. This lack of real consequences is both a weakness and the strength of the Amplifon project. The non-reality of the Amplifon project is productive in that it allows us to propose profound replacements in technology and journalistic procedures without concern for the manifold bureaucratic and financial complexities involved in actually doing it in the real world. An academic prototype has little direct impact on the real world compared with well-established, license fee-financed broadcasters like NRK and upstarts like Capsule.FM. The project team describes possible care-structures that were discovered and tested during the experimental phase, but it does not launch an actual new medium that actually increases the communicative concern for real headphone users. It is a hypothetical medium, created in order to provoke reflections on good and less good components of a medium, and to generate novel academic analyses and their publication.

The central weakness of an academic prototype project is that we cannot draw strong conclusions. We cannot authoritatively claim that the proposals made in this article are the best way forward, or that they will actually solve the problem of lack of communicative concern for headphone users. Indeed, many people may not even acknowledge that there is a problem on this score, at least not until they have experienced a high quality locative service and can compare it with the current offerings. In this sense, the Amplifon as a hypothetical design project is utterly speculative.

Another weakness it that the project could not address all the very important ethical issues triggered during the experimental phase. While being a research project, it was nevertheless an editorial platform at the same time, and we were not sufficiently aware of this at the start. Questions of editorial responsibility, ownership and copyrights abounded, not just in relation to the students creating original content, but also in relation to the use of recorded music and clips of other already copyrighted audio material. Future projects in the field of academic media prototyping should prepare carefully for issues of responsibility and editorial platform.

There are also complications due to the fundamental uncertainty of technological innovation. The research team shapes a technology and its attendant procedures according to knowledge of how its components typically behave in practice, as observed so far. However, once the technology is let loose in society it starts to associate with other media in ways that are impossible to foresee. Researchers simply cannot state in advance what kind of impact a new medium will have on society, but can at best hope to change the direction of development in a sector of the industry for a limited period of time. 


\section{ACKNOWLEDGEMENTS}

Many thanks for valuable contributions from colleagues Bjørnar Tessem, Jon Hoem, Eirik Stavelin, Kjartan Michalsen and Stein Unger Hitland and students Mari Anvik Berg, Morten Dahle, Øyvind Hjartnes, Darko Mrdalj, Petter Omdal, Eileen K. Osmo, Ørjan Blytt Polden, Karoline Erstad Raudstein, Kamilla Svendsen and Joakim Vindenes.

\section{REFERENCES}

Behrendt, F. (2012). The sound of locative media, in Convergence 18(3): 283-297.

Behrendt, F. (2015). Locative Media as Sonic Interaction Design: Walking Through Placed Sounds. Wi: Journal of Mobile Media. 9(2): 25 pages.

Bull, M. (2000). Sounding Out the City. Personal Stereos and the Management of Everyday Life. Oxford: Berg.

Bull, M. (2007). Sound Moves: iPod Culture and Urban Experience. London: Routledge.

Casey, Edward (1993) Getting Back into Place: Toward a Renewed Understanding of the Place-World. Bloomington: Indiana University Press.

Couldry, N. (2012). Media, Society, World: Social Theory and Digital Media Practice. Oxford: Polity.

Dewey, J. (1908/1960]. Theory of the Moral Life. New York: Holt, Rinehart and Winston.

Dewey, John. (1927/1991). The Public and its Problems. Athens: Swallow Press.

DiSalvo, C. (2009). Design and the Construction of Publics, in Design Issues 25(1): 48-63.

Fagerjord, A. (2011). Between Place and Interface: Designing Situated Sound for the iPhone. Computers and Composition 28: 255-263. DOI: http://dx.doi. org/10.1016/j.compcom.2011.07.001
Fagerjord, A. (2015) Humanist Evaluation Methods in Locative Media Design. The Journal of Media Innovations, 2(1): 107-22. DOI: http://dx.doi. org/10.5617/jmi.v2i1.893

Farman, Jason. (Ed.) (2014) The Mobile Story: Narrative Practices with Locative Technologies. London: Routledge.

Gordon, E. and A. De Souza e Silva. (2011). Net Location. Why location matters in a networked world. Oxford: Wiley-Blackwell.

du Guy, P., S. Hall, L. Janes, H. Mackay, K. Negus (1997). Doing Cultural Studies. The Story of the Sony Walkman. London: Sage.

High, S. (2013) Embodied Ways of Listening: Oral History, Genocide and the Audio Tour. Anthropologica 55(1): 73-85.

Jauert, P. and G. F. Lowe (2005). Public Service Broadcasting for Social and Cultural Citizenship. Renewing the Enlightenment Mission. G.F. Lowe and P. Jauert (eds.) Cultural Dilemmas in Public Broadcasting Service, pp. 15-32. Gothenburg: Nordicom.

Ladly, M. (2008) Report. Designing for Mobile: A Walk in the Park. Canadian Journal of Communication, 33(3): 525-536. 
Liestøl, G. (2009). Situated Simulations: A Prototyped Augmented Reality Genre for Learning on the iPhone. International Journal of Interactive Mobile Technologies 3 (2009) Special Issue IMCL2009.

Liestøl, G. (2013). Topics of innovation. Towards a method of invention and innovation in digital media design. T. Storsul and A. Krumsvik (eds.) Media Innovations: A Multidisciplinary Study of Change, pp. 61-74. Gøteborg: Nordicom.

Liestøl, G., Rasmussen, T. \& Stenarson, T. (2011) Mobile innovation: designing and evaluating situated simulations. Digital Creativity 22 (3), 174-186.

Lynch, K. (1960). The Image of the City. Cambridge, Mass.: MIT Press.

Løvlie, A. S. (2011). Textopia. Experiments with Locative Literature. Doctoral dissertation at the University of Oslo.

Milgram, S. (1976). Psychological Maps of Paris. In Environmental Psychology: People and Their Physical Settings. New York: Holt, Rinehart and Winston, pp. 104-124.

Nyre, Lars (2007) Minimum Journalism. Experimenta procedures for democratic participation in sound media. Journalism Studies 8(3): 397-413.
Nyre, Lars (2008) Sound Media. From live journalism to musical recording. London: Routledge.

Nyre, Lars (2011) The Broadcast Pulic and Its Problems. Javnost - The Public 18(2): 5-18.

Nyre, Lars (2014a) Media design method. Combining media studies with design science to make new media. Journal of Media Innovations 1(1). DOI: http:// dx.doi.org/10.5617/jmi.v1i1.702

Nyre, Lars (2014b) Amplifon. På sporet av et mer intelligent radiomedium. Nordicom-Information 36(4): 92-96.

Nyre, Lars (2015) Urban Headphone Listening and the Situational Fit of Music, Radio and Podcasting. Journal of Radio and Audio Media 22(2).

Nyre, Lars; Bjørnestad, Solveig; Tessem, Bjørnar; Øie, Kjetil Vaage (2012) Locative journalism: Designing a location-dependent news medium for smartphones. Convergence. The International Journal of Research into New Media Technologies 18(3): 297-314.

O’Neill, B., M. Ala-Fossi, P. Jauert, L. Nyre and H. Shaw. (2010). Digital Radio in Europe: Technologies, Industries and Culture. London: Intellect.

Scannell, P. (2014). Television and the Meaning of 'Live': An Enquiry into the Human Situation. London: Polity.
Simun, M. (2009). My music, my world: using the MP3 player to shape experience in London. New Media \& Society 11(6): 921-941.

Steinbock, D. (2005). The Mobile Revolution. The Making of Mobile Services Worldwide. London: Kogan Page.

Stilgoe, Jack, Richard Owen \& Phil Macnaghten (2013) Developing a framework for responsible innovation. Research Policy 42: 1568-1580.

Tessem, B., B. Johansen, C. Veres (2013). Mobile Location-Driven Associative Search in DBpedia with Tag Clouds. CEUR Workshop Proceedings 1026: 6-10.

Urry, J. (2007). Mobilities. Oxford: Polity.

Väätäjä, H. 2014. Framing the user experience in mobile newsmaking with smartphones. Doctoral thesis Tampere University of Technology.

Wilken, R. and G. Goggin. 2014. Locative Media. New York: Routledge.

Øie, K. V. (2012). Sensing the News: User Experiences when Reading Locative News. Future Internet 4(4). DOI: http://dx.doi.org/10.3390/fi4010161.

Øie, K. V. (2015) News Narratives in Locative Journalism. Forthcoming in Journal of Media Practice. 